\title{
PENGARUH PENGGUNAAN IPTABLES FIREWALL DAN ACID TERHADAP KEAMANAN JARINGAN
}

\author{
Realize $^{1}$, Uni Hananti ${ }^{2}$ \\ ${ }^{1,2}$ Fakultas Teknik Universitas Putera Batam \\ Email: ${ }^{1}$ realize.eel@gmail.com \\ Submitted: 16-03-2017, Reviewed: 17 -03- 2017, Accepted 18-03-2017 \\ http://dx.doi.org/10.22202/jei.2017.v3i2.1896
}

\begin{abstract}
Network security is very important in a company. Iptables firewall is one type of firewall that has the innate advantages of linux can filter incoming data packets into a firewall and Analysis Console for Intrusioan Database (ACID) can serve as a database for storing and all types of attacks that go into the firewall. So with the iptables firewall and Analysis Console for Intrusioan Database (ACID) Batamindo industrial park batam company can be maintained network security. The purpose of this research is intended to obtain data and information on the effect of iptables firewall and Analysis Console for Instrusion Databases (ACID) to the Company's network security in the region Batamindo Indusrial Park Batam
\end{abstract}

Keywords: Iptables firewal, Analysis Console for Instrusion Databases (ACID), network security.

\section{PENDAHULUAN}

Batam Bintan Telekomunikasi (BBT) adalah perusahaan patungan antara PT. Batamindo Invesment Cakrawala (BIC), dahulu bernama PT. Batamindo Invesment Corporation dengan PT. Telekomunikasi Indonesia (TELKOM) yang bergerak dalam bidang jasa penyelenggaraan jaringan dan jasa telekomunikasi yang beroperasi di Kawasan Industri Mukakuning pulau Batam, Kawasan Industri Lobam dan Kawasan Resort Lagoi di pulau Bintan. Batamindo Industrial Park adalah suatu kawasan yang terletak di Muka Kuning Batam. Di kawasan ini terdapat sekitar 68 perusahaan yang rata-rata bergerak di bidang Elektronik dan pada umumnya merupakan perusahaan asing.

Dalam perkembangan teknologi sekarang ini banyak perusahaan yang menggunakan komputer sebagai media informasi atau alat untuk mengirim dan menyimpan data yang berfungsi untuk mempermudah dalam melakukan pekerjaannya. Pentingnya data dalam suatu perusahaan membuat perusahaan itu sendiri harus mempunyai alat atau sistem yang dapat melindungi data dari hal seperti pencurian data, rusaknya data, hilangnya data dan terhapusnya suatu data. Pentingnya perlindungan data membuat perusahaan memerlukan karyawan bagian IT yang bertugas untuk mengamankan data atau jaringan dari tindak penyusupan, serangan dan pencurian data.

Menurut Sofana (2008: 3-7) jaringan komputer diklasifikasikan menjadi tiga, yaitu:

1. Berdasarkan Area atau Skala, jaringan komputer dibagi menjadi empat jenis, yaitu Local Area Network (LAN), Metropolitan Area Network (MAN), Wide Area Network (WAN) dan Internet.

Tabel 1. Jaringan komputer berdasarkan Area

\begin{tabular}{|c|c|c|}
\hline $\begin{array}{c}\text { Jarak/Cangkupan } \\
\text { (mater) }\end{array}$ & Contoh & Jenis \\
\hline $10 \mathrm{~s} / \mathrm{d} 100$ & Ruangan & LAN \\
\hline $100 \mathrm{~s} / \mathrm{d} 1000$ & Gedung & LAN \\
\hline $1000 \mathrm{~s} / \mathrm{d} 10.000$ & Kampus & LAN \\
\hline $10.000 \mathrm{~s} / \mathrm{d}$ & Kota & MAN \\
100.000 & & \\
\hline $\begin{array}{c}100.000 \mathrm{~s} / \mathrm{d} \\
1.000 .000\end{array}$ & Negara & WAN \\
\hline $\begin{array}{c}1.000 .000 \mathrm{~s} / \mathrm{d} \\
10.000 .000\end{array}$ & Benua & WAN \\
\hline$>10.000 .000$ & Planet & Internet \\
\hline
\end{tabular}

Sumber: Yani (2008: 5) 
2. Berdasarkan Media Penghantar, jaringan komputer dapat dibagi menjadi dua jenis, yaitu Wire Network dan Wireless Network

3. Berdasarkan Fungsi, jaringan komputer dapat dibagi menjadi dua jenis, yaitu Client Server dan Peer to Perr.

Sistem Operasi adalah pengelola seluruh sumber daya yang terdapat pada sistem komputer dan menyediakan sekumpulan layanan (system call) ke pemakai sehingga memudahkan dan menyamakan penggunaan serta pemanfaatan sumber daya sistem komputer (Pangera, dkk, 2005: 2). Linux merupakan salah satu sistem operasi yang bisa dijadikan sebagai server yang menyediakan tools berupa iptables yang berfungsi sebagai firewall untuk menjaga integritas data dari server linux terhadap serangan-serangan cracker yang tidak bertanggung jawab, dengan cara memfilterisasi paket-paket yang akan masuk.

Menurut Purdy (2004: 1) Iptables is architecture groups network packet processing rules into tables by function (packet filtering, networks address translation, and other packet mangling) each of which have chains (sequences) of processing rules. Rules consist of matches (used to determine what will be done with the matching packets). Iptables devines five "hook point" in the kernel's packet processing pathways: PREROUTING, INPUT, FORWARD, POSTROUTING and OUTPUT. Built-in chains are attached to these hook points; you can add sequence of rules for each hook point. Each rule represents an opportunity to affect or monitor packet flow.

Iptables dapat disimpulkan bahwa iptables merupakan suatu firewall bawaan dari linux yang berfungsi untuk menganalisis dan menyaring paket data yang masuk kedalam firewall, apakah paket data tersebut akan di-drop (membiarkan paket tersebut seolah-olah tidak pernah diterima), di-accept (menerima paket tersebut untuk diproses lebih lanjut), atau di-reject (menolak dan memberitahu pengirim bahwa paket data tidak bisa diterima). Iptables juga sebagai alat untuk menyaring paket-paket yang masuk, keluar dan sedang berlalu lintas didalam Firewall melalui server. Menurut Yani dan Hafiarny (2005: 71) ada tiga kegunaan dari Iptables, yaitu: 1) Membatasi akses ke jaringan kita untuk traffic data tertentu saja; 2) Memfilter serangan luar; 3) Membatasi akses ke service-service dalam komputer kita. Adapun indikator yang digunakan dalam iptables firewall adalah sebagai berikut (Purdy, 2004: 911): (1) Packet filtering; (2) Accounting; (3) Connection tracking; (4) Packet mangling; (5) Network address translation (NAT); (6) Masquerading; (7) Port Forwarding; (8) Load balancing.

Berikut adalah Diagram Perjalanan Paket data pada Iptables Firewall:

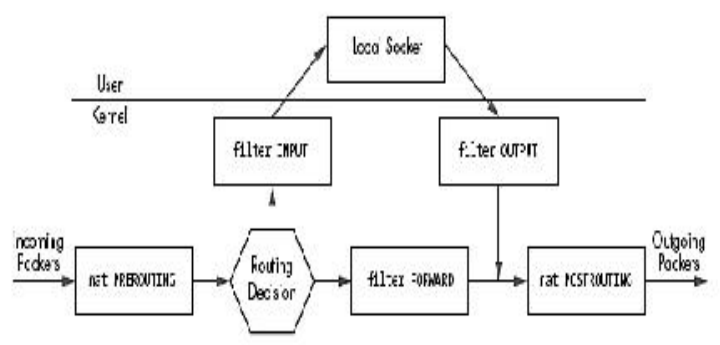

Sumber: Rash (2007: 11).

\section{Gambar 1. Diagram perjalanan paket data pada Iptables}

Dalam sebuah sistem keamanan jaringan selain menggunakan Iptables sebagai Firewall perusahanan juga membutuhkan Analysis Console for Intrusion Databases (ACID) yang berfungsi sebagai alat yang digunakan untuk menganalisa dan menyajikan data snort menggunakan antar muka dan ditulis dalam PHP. ACID bekerja dengan membaca database seperti MySQL dan sebagai alat keamanan jaringan. Menurut Drive (2010: 39) Analysis Console for Intrusion Databases (ACID) Is php-based analysis engine to search and process a database of security events generated by various IDS, Firewalls, and network monitoring tools. Dan menurut Koff et al., (2005: 353), Analysis Console for Intrusion Databases (ACID) Is a PHP based system for querying and analyzing Network based IDS (NIDS) alerts. ACID is designed to be a general-purpose intrusion detection analysis system. It is not focused simply snort, ACID can pull in firewall logs and raw TCP dumps as well.

Analysis Console for Intrusion Databases $(A C I D)$ adalah alat yang disajikan mengunakan database MySQL. Analysis Console for Intrusion Databases (ACID) ditulis mengunakan bahasa pemprograman $p h p$, yang berfungsi sebagai alat untuk menganalisis data yang berasal dari Firewall, IDS (Intrusion Detection System) dan alat pemantau jaringan. Analysis Console for Intrusion Databases (ACID) juga mempunyai kemampuan grafis dasar yang membantu pengguna/user untuk menampilkan peringatan 


\section{Jurnal EdikInformatika}

Penelitian Bidang Komputer Sains dan Pendidikan Informatika V3.i2(157-164)

berdasarkan hari, jam, bulan. Contoh untuk sedangkan komputer adalah suatu yang meliputi mendeteksi peringatan selama 24 jam user dapat CPU (Prosesor), memori, I/O Device, dan memilih grafis peringatan waktu deteksi dan sebagainya. Jadi security komputer adalah segala kemudian memasukan bulan, hari dan tahun yang sesuatu yang mengenai keamanan bagi sistem diinginkan.

komputer filosofi (dasar pemikiran) keamanan

Adapun indikator yang digunakan dalam komputer agar dapat mengamankan dengan benar. Analysis Console for Intrusion Databases (ACID) Adapun pengertian keamanan jaringan menurut adalah sebagai berikut: (1) Query-builder and Maslan dan Wangdra (2012: 143), Teknologi search interface; (2) Packet viewer (decoder); (3) keamanan jaringan atau keamanan data (security) An alert management system; (4) A charting and adalah meningkatkan akan segala sesuatu yang statistics generator; (5) Tools to analyze.

Menurut Na'am (2012: 8), security adalah pembatasan akses data. segala sesuatu yang mengenai keamanan,

Tabel 2. Ancaman Terhadap Keamanan

\begin{tabular}{|c|c|c|c|}
\hline System & Avability & Secrecy & Integrity \\
\hline Hardware & Dicuri atau dirusak & & \\
\hline $\begin{array}{r}\text { Software } \\
\text { Line komunikasi }\end{array}$ & Program dihapus & Software di copy & $\begin{array}{c}\text { Program } \\
\text { dimodifikasi }\end{array}$ \\
\hline $\begin{array}{c}\text { Kabel diputus } \\
\text { dirusak }\end{array}$ & Infornasi disadap & $\begin{array}{c}\text { Informasi } \\
\text { dimodifikasi }\end{array}$ \\
\hline
\end{tabular}

Sumber: Ariyus (2008: 9)

Menurut Ariyus dalam kamus hacker (2005: 208) Networks Security adalah ketika suatu sistem bertambah besar, penjagaan keamanan dengan memeriksa host demi host yang ada di sistem menjadi tidak pasti. Dengan pendekatan keamanan jaringan, maka usaha tersebut dikonsentrasikan dengan mengontrol akses ke jaringan pada sistem. Dan pengertian Network Security menurut Samuelle (2009: 95) adalah In additional to dIviding the network physically into zones to secure network communications, you can use several software based network configurations to aid in securing your netwok from unauthorized intruders. these enable you to reconfigure the network logically instead of physically, which reduces administrative overhead and removes the need to purchase additional expensive equipment."

Ancaman Keamanan yang terjadi terhadap informasi menurut Ariyus (2008: 9), yaitu: 1) Interuptsion; 2) Interception; 3) Modification; 4) Fabrication. Celah - celah keamanan jaringan yang paling serius pada semua jenis sistem menurut Tittel (2004: 238-239), adalah sebagai berikut: 1) Konfigurasi default system operasi dan berbagai aplikasi lainnya; 2) Account yang tidak dilindungi oleh password atau dilindungi password yang lemah; 3)Ketiadaan atau ketidaklengkapan data backup; 4) banyaknya jumlah port yang terbuka; 5) Tidak melaksanakan penyaringan paket-paket untuk memastikan kebenaran alamat pengirim dan alamat tujuannya; 6) Ketiadaan atau ketidaklengkapan catatan log; 7) Celah-celah pada program $C G I$.

Menurut Ariyus (2008: 9-10) ada delapan Aspek dari keamanan Jaringan Komputer, yaitu sebagai berikut: (1) Authentication; (2) Integrity; (3) Non-repudiation; (4) Authority; (5) Confidentiality; (6) Privacy; Availability; (8) Acesss Control.

\section{METODE PENELITIAN}

Metode yang digunakan dalam penelitian ini adalah metode verifikatif. Metode ini digunakan untuk mengetahui pengaruh Iptables Firewall dan Analysis Console for Intrusion Databases (ACID) terhadap keamanan Jaringan pada Perusahaan di Kawasan Batamindo Indusrial Park Batam. Populasi dalam penelitian ini adalah karyawan bagian IT 


\section{Jurnal EdikInformatika}

Penelitian Bidang Komputer Sains dan Pendidikan Informatika V3.i2(157-164)

yang bekerja di perusahaan Kawasan Batamindo Industrial Park di kota Batam dengan populasi sebanyak 138 karyawan bagian IT dengan jumlah sampel sebanyak 103 sampel. Pada penelitian ini pengumpulan data primer dilakukan menggunakan metode survey, yaitu dengan menggunakan kuisioner. Kuesioner merupakan suatu pengumpulan data dengan memberikan atau menyebarkan daftar pertanyaan/pernyataan kepada responden dengan harapan memberikan respons atas daftar pertanyaan tersebut (Umar, 2011: 49).

\section{HASIL DAN PEMBAHASAN Hasil Uji Validitas Data}

Berdasarkan hasil analisis data dari ketiga variabel-varibel yang telah dibahas sebelumnya, maka pengujian validitas disimpulkan sebgai berikut:

Tabel 3. Hasil Uji Validitas variabel $\mathbf{X}_{\mathbf{1}}$

\begin{tabular}{|l|r|r|r|r|r|}
\hline & $\begin{array}{l}\text { Scale Mean if } \\
\text { Item Deleted }\end{array}$ & $\begin{array}{l}\text { Scale Variance if } \\
\text { Item Deleted }\end{array}$ & $\begin{array}{l}\text { Corrected Item- } \\
\text { Total Correlation }\end{array}$ & $\begin{array}{l}\text { Squared Multiple } \\
\text { Correlation }\end{array}$ & $\begin{array}{l}\text { Cronbach's Alpha } \\
\text { if Item Deleted }\end{array}$ \\
\hline X1.1 & 27.82 & 13.681 & .448 & .235 & .825 \\
X1.2 & 27.75 & 13.328 & .701 & .985 & .784 \\
X1.3 & 27.64 & 14.703 & .595 & .998 & .802 \\
X1.4 & 27.73 & 13.435 & .677 & .999 & .787 \\
X1.5 & 27.62 & 14.806 & .555 & .998 & .806 \\
X1.6 & 27.76 & 13.225 & .701 & .998 & .783 \\
X1.7 & 27.69 & 14.432 & .576 & .961 & .802 \\
X1.8 & 27.76 & 15.048 & .284 & .226 & .846 \\
\hline
\end{tabular}

Sumber: Pengolahan data

Tabel 4. Hasil Uji Validitas validitas $X_{2}$

\begin{tabular}{|l|r|r|r|l|r|}
\hline & $\begin{array}{l}\text { Scale Mean if } \\
\text { Item Deleted }\end{array}$ & $\begin{array}{l}\text { Scale Variance if } \\
\text { Item Deleted }\end{array}$ & $\begin{array}{l}\text { Corrected Item- } \\
\text { Total Correlation }\end{array}$ & $\begin{array}{l}\text { Squared Multiple } \\
\text { Correlation }\end{array}$ & $\begin{array}{l}\text { Cronbach's Alpha } \\
\text { if Item Deleted }\end{array}$ \\
\hline X2.1 & 16.62 & 5.022 & .465 & .278 & .665 \\
X2.2 & 16.55 & 5.191 & .530 & .299 & .644 \\
X2.3 & 16.50 & 4.958 & .409 & .256 & .692 \\
X2.4 & 16.39 & 4.907 & .558 & .471 & .628 \\
X2.5 & 16.26 & 5.117 & .409 & .409 & .689 \\
\hline
\end{tabular}

Sumber: Pengolahan data

Tabel 5. Hasil uji validitas $Y$

\begin{tabular}{|l|r|r|r|r|r|}
\hline & $\begin{array}{l}\text { Scale Mean if } \\
\text { Item Deleted }\end{array}$ & $\begin{array}{l}\text { Scale Variance if } \\
\text { Item Deleted }\end{array}$ & $\begin{array}{l}\text { Corrected Item- } \\
\text { Total Correlation }\end{array}$ & $\begin{array}{l}\text { Squared Multiple } \\
\text { Correlation }\end{array}$ & $\begin{array}{l}\text { Cronbach's Alpha } \\
\text { if Item Deleted }\end{array}$ \\
\hline Y1 & 29.35 & 10.406 & .439 & .261 & .797 \\
Y2 & 29.19 & 10.080 & .572 & .889 & .794 \\
Y3 & 29.18 & 9.505 & .570 & .894 & .777 \\
Y4 & 29.03 & 10.342 & .500 & .867 & .788 \\
Y5 & 29.23 & 9.926 & .584 & .887 & .776 \\
Y6 & 29.19 & 9.785 & .597 & .876 & .774 \\
Y7 & 29.01 & 10.500 & .469 & .867 & .792 \\
Y8 & 29.46 & 9.564 & .466 & .311 & .798 \\
\hline
\end{tabular}

Sumber: Pengolahan data

Dari hasil uji validitas data pada variabel independen yakni Iptables Firewall dan Analysis Console for Intrusion Databases (ACID dan validitas dependen yaki Keamanan
Jaringan diketahui bahwa nilai Corrected ItemTotal Correlation masing-masing variabel tersebut lebih besar dari nilai r-table $(0,1937)$, sehingga dapat disimpulkan bahwa setiap 
instrumen dari variabel dinyatakan valid dan dapat digunakan.

\section{Hasil Uji Reliabilitas}

Tabel 6. Hasil Uji Reliabilitas variabel $X_{1}$ Reliability Statistics

\begin{tabular}{|l|l|l|}
\hline $\begin{array}{l}\text { Cronbach's } \\
\text { Alpha }\end{array}$ & $\begin{array}{l}\text { Cronbach's } \\
\text { Alpha Based on } \\
\text { Standardized } \\
\text { Items }\end{array}$ & \\
\hline .825 & .840 & N of Items \\
\hline
\end{tabular}

Sumber: Pengolahan data

Tabel 7. Hasil Uji Reliabilitas variabel $\mathrm{X}_{2}$ Reliability Statistics

\begin{tabular}{|l|l|l|}
\hline $\begin{array}{l}\text { Cronbach's } \\
\text { Alpha }\end{array}$ & $\begin{array}{l}\text { Cronbach's } \\
\text { Alpha Based on } \\
\text { Standardized } \\
\text { ltems }\end{array}$ & \\
\hline .712 & .719 & N of Items \\
\hline
\end{tabular}

Sumber: Pengolahan data

Tabel 8. Hasil Uji Reliabilitas variabel Y Reliability Statistics

\begin{tabular}{|l|l|l|}
\hline $\begin{array}{l}\text { Cronbach's } \\
\text { Alpha }\end{array}$ & $\begin{array}{l}\text { Cronbach's } \\
\text { Alpha Based on } \\
\text { Standardized } \\
\text { Items }\end{array}$ & N of Items \\
\hline .807 & .812 & 8 \\
\hline
\end{tabular}

Sumber: Pengolahan data

Dari hasil uji reliabilitas pada variabel independen yaitu Iptables Firewall dan Analysis Console for Intrusion Databases (ACID) dan variabel dependen yaitu Keamanan Jaringan diketahui bahwa nilai koefisien variansi (Cronbach's Alfa) masing-masing variabel tersebut lebih besar dibandingkan daripada 0,6 sehingga dapat disimpulkan bahwa seluruh variabel reliabel dan dapat dijadikan sebagai instrument pengukuran.

\section{Hasil Uji Normalitas Data}

Tabel 9. Hasil Uji Normalitas Data

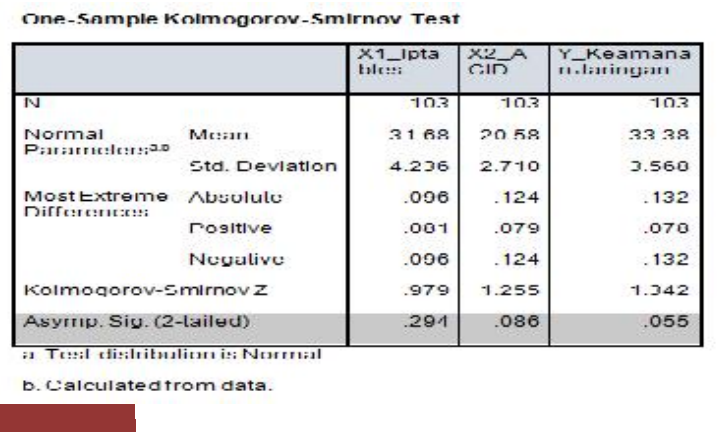

\section{Sumber: Pengolahan data}

Berdasarkan tabel 7 diketahui nilai Kolmogorov Smirnov memiliki distribusi normal karena memiliki tingkat signifikasi lebih dari 0,05 , yakni untuk variabel $\left(X_{1}\right)$ sebesar 0,294, $\left(\mathrm{X}_{2}\right)$ sebesar 0.86 dan variabel $\mathrm{Y}$ sebesar 0,055. Hal ini menunjukkan bahwa data sudah berdistribusi dengan normal.

\section{Hasil Uji Heteroskedastisitas}

Uji heterokedastisitas dilakukan untuk mengetahui apakah dalam sebuah model regresi terjadi ketidaksamaan varians dari residual suatu pengamatan ke pengamatan lain. Jika varians dari residual suatu pengamatan ke pengamatan tetap disebut homoskedastisitas, sementara itu, untuk varians yang berbeda disebut heteroskedastisitas. Model regresi yang baik adalah tidak terjadi heteroskedastisitas (Umar, 179: 2011).

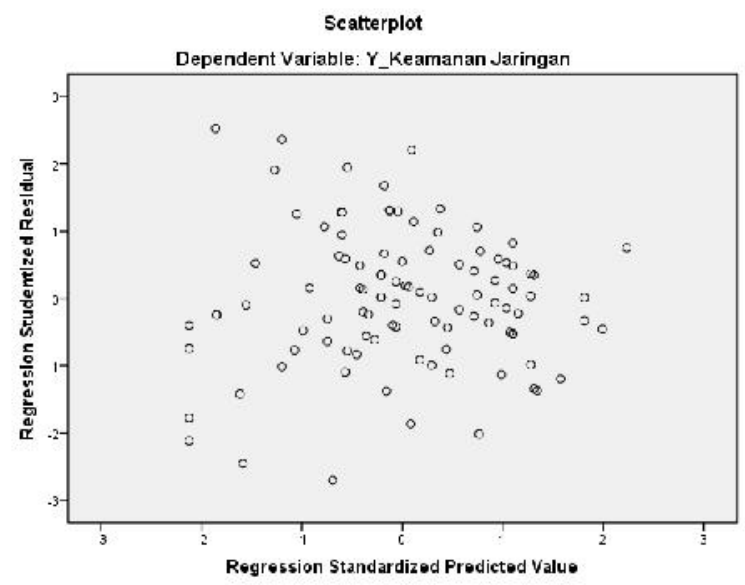

Gambar 2. Uji Heterokedastisitas

Berdasarkan gambar diatas, dapat dilihat titik-titik pada scatter plot terlihat menyebar, hal ini menunjukan bahwa data tersebut berdistribusi normal.

\section{Hasil Uji Multikolinieritas}

Uji multikolinieritas untuk mengetahui apakah pada model regrasi ditemukan adanya korelasi antar variabel independen (Iptables Firewall dan Analysis Console for Intrusion Databases). Jika terjadi korelasi, terdapat masalah multikolinieritas yang harus diatasi. 
Tabel 10. Hasil Uji Multikolinieritas

Coefficients $^{\mathrm{a}}$

\begin{tabular}{|c|c|c|c|c|c|c|c|c|}
\hline \multirow{2}{*}{\multicolumn{2}{|c|}{ Model }} & \multicolumn{2}{|c|}{$\begin{array}{l}\text { Unstandardized } \\
\text { Coefficients }\end{array}$} & \multirow{2}{*}{$\begin{array}{l}\text { Standardized } \\
\text { Coefficients } \\
\text { Beta }\end{array}$} & \multirow[b]{2}{*}{$\mathrm{t}$} & \multirow[b]{2}{*}{ Sig. } & \multicolumn{2}{|l|}{$\begin{array}{l}\text { Collinearity } \\
\text { Statistics }\end{array}$} \\
\hline & & $B$ & Std. Error & & & & Tolerance & VIF \\
\hline 1 & (Constant) & 13.613 & 3.004 & & 4.532 & .000 & & \\
\hline & X1_Iptables & .354 & .071 & .420 & 5.010 & .000 & .986 & 1.015 \\
\hline & X2_ACID & .416 & .110 & .316 & 3.772 & .000 & .986 & 1.015 \\
\hline
\end{tabular}

a. Dependent Variable: $Y \_$Keamanan Jaringan

Sumber: Pengolahan data

Berdasarkan hasil perhitungan diatas terlihat bahwa Variance Inflation Factor (VIF) dari masing-masing variabel yaitu Iptables Firewall $(1,015)$ dan Analysis Console for Intrusion Databases (ACID) (1,015) kurang dari 10. Sehingga dapat diambil kesimpulan bahwa model tidak terdapat (tidak terjadi)

\section{Hasil Uji Korelasi}

Korelasi adalah mengukur keeratan suatu hubungan, keeratan suatu hubungan ini dinyatakan dengan besaran korelasi (r) yang nilainya berada dalam rentang -1 sampai 1 . multikolinearitas.

Correlations

\section{Tabel 11. Hasil Uji Korelasi}

\begin{tabular}{|c|c|c|c|c|}
\hline & & X1_Iptables & X2_ACID & $\begin{array}{l}\text { Y_Keamanan } \\
\text { Jaringan }\end{array}$ \\
\hline \multirow[t]{3}{*}{ X1_Iptables } & Pearson Correlation & 1 & .120 & $.458^{n}$ \\
\hline & Sig. (2-tailed) & & .228 & .000 \\
\hline & $\mathrm{N}$ & 103 & 103 & 103 \\
\hline \multirow[t]{3}{*}{ X2_ACID } & Pearson Correlation & .120 & 1 & $.366^{\pi *}$ \\
\hline & Sig. (2-tailed) & .228 & & .000 \\
\hline & $\mathrm{N}$ & 103 & 103 & 103 \\
\hline \multirow[t]{3}{*}{ Y_Keamanan Jaringan } & Pearson Correlation & $.458^{m}$ & .366 & 1 \\
\hline & Sig. (2-tailed) & .000 & .000 & \\
\hline & $\mathrm{N}$ & 103 & 103 & 103 \\
\hline
\end{tabular}

Sumber: Pengolahan Data

Dari tabel diatas, dapat diambil kesimpulan bahwa Iptables Firewall memiliki korelasi yang lemah, hal ini dibuktikan dengan nilai Person Correlation sebesar 0,458 dan variabel Analysis Console for Intrusion Databases (ACID memiliki korelasi yang lemah, hal ini dibuktikan dengan nilai Person Correlation sebesar 0,366.

\section{Hasil Uji R dan R Square}

Uji R (koefisien korelasi) digunakan untuk mengukur keeratan hubungan antar variabel respon atau variabel dependen dengan variabel independen (penjelas). Sedangkan uji R Square $\left(\mathrm{R}^{2}\right)$ disebut juga nilai koefisien deteminasi, nilai yang digunakan untuk melihat sejauh mana model yang terbentuk dapat menjelaskan kondisi yang sebenarnya.
Model Summary ${ }^{\mathrm{D}}$

\begin{tabular}{|c|c|c|c|c|c|c|c|c|c|}
\hline \multirow[b]{2}{*}{ Model } & \multirow[b]{2}{*}{$\mathrm{R}$} & \multirow[b]{2}{*}{\begin{tabular}{|l}
$R$ \\
Square
\end{tabular}} & \multirow[b]{2}{*}{$\begin{array}{l}\text { Adjusted } \\
\text { R Square }\end{array}$} & \multirow{2}{*}{$\begin{array}{l}\text { Std. Error } \\
\text { of the } \\
\text { Estimate }\end{array}$} & \multicolumn{5}{|c|}{ Change Statistics } \\
\hline & & & & & $\begin{array}{l}\text { R Square } \\
\text { Change }\end{array}$ & $\begin{array}{l}\text { F } \\
\text { Change }\end{array}$ & df1 & df2 & $\begin{array}{l}\text { Sig. F } \\
\text { Change }\end{array}$ \\
\hline
\end{tabular}


Penelitian Bidang Komputer Sains dan Pendidikan Informatika V3.i2(157-164)

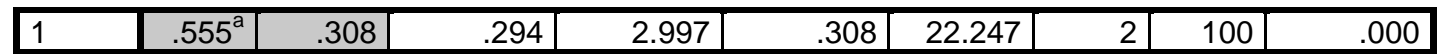

a. Predictors: (Constant), X2_ACID, X1_Iptables

b. Dependent Variable: Y_Keamanan Jaringan

Sumber: Pengolahan data

Berdasarkan table diatas, dapat dilihat nilai R Squarenya adalah 0.308 yang artinya $30,80 \%$ Iptables Firewall dan Analysis Console for Intrusion Database (ACID) dapat dijelaskan oleh variabel keamanan jaringan, sedangkan $69,20 \%$ dipengaruhi oleh variabel lain yang tidak diteliti. Kemudian untuk nilai $\mathrm{R}$ adalah 0,555 kolerasi antara variabel $\mathrm{X}_{1}$ dan $\mathrm{X}_{2}$ secara bersamaan dengan $\mathrm{Y}$ adalah 0,555.

\section{Hasil Uji t (Partial)}

Uji ini bertujuan untuk mengetahui pengaruh variabel Iptables Firewall dan Analysis Console for Intrusion Database $(A C I D)$ terhadap Keamanan Jaringan.

\section{Coefficients $^{\mathrm{a}}$}

Tabel 13. Hasil Uji t (Partial)

\begin{tabular}{|c|c|c|c|c|c|c|c|}
\hline \multirow[b]{2}{*}{ Model } & \multicolumn{2}{|c|}{$\begin{array}{l}\text { Unstandardized } \\
\text { Coefficients }\end{array}$} & \multirow{2}{*}{\begin{tabular}{|l}
$\begin{array}{l}\text { Standardized } \\
\text { Coefficients }\end{array}$ \\
Beta \\
\end{tabular}} & \multirow[b]{2}{*}{$\mathrm{T}$} & \multirow[b]{2}{*}{ Sig. } & \multicolumn{2}{|l|}{$\begin{array}{l}\text { Collinearity } \\
\text { Statistics }\end{array}$} \\
\hline & $\mathrm{B}$ & Std. Error & & & & Tolerance & VIF \\
\hline 1 (Constant) & 13.613 & 3.004 & & 4.532 & .000 & & \\
\hline X1_Iptables & .354 & .071 & .420 & 5.010 & .000 & .986 & 1.015 \\
\hline X2_ACID & .416 & .110 & .316 & 3.772 & .000 & .986 & 1.015 \\
\hline
\end{tabular}

a. Dependent Variable: $Y \_$Keamanan Jaringan

Sumber: Pengolahan data

Pada tabel diatas, dapat diketahui bahwa nilai t-hitung variabel Iptables Firewall (X1) adalah sebesar 5,010 dengan nilai Signifikan sebesar 0,000 . Hal ini berarti bahwa nilai thitung > nilai t-tabel yaitu 5,010>1,9837. Artinya hasil uji t ini menunjukkan bahwa variabel Iptables Firewall mempunyai pengaruh yang positif dan signifikan terhadap Keamanan Jaringan.
Sedangkan nilai t-hitung variabel Analysis Console for Intrusion Database (ACID) adalah sebesar 3,772 dengan nilai Signifikan sebesar 0,000. Hal ini berarti bahwa nilai t-hitung > nilai t-tabel yaitu $3,772>1,9837$ dengan kesimpulan $\mathrm{H}_{1}$ diterima karena $0,000<0,05$. Artinya hasil uji t ini menunjukkan Analysis Console for Intrusion Database (ACID) mempunyai pengaruh yang positif dan signifikan terhadap Keamanan Jaringan.

\section{Hasil Uji F}

ANOVA $^{b}$

\section{Tabel 14. Hasil Uji F (Simultan)}

\begin{tabular}{|l|r|r|r|r|r|}
\hline Model & Sum of Squares & Df & Mean Square & F & Sig. \\
\hline \hline Regression & 399.768 & 2 & 199.884 & 22.247 & $.000^{a}$ \\
Residual & 898.465 & 100 & 8.985 & & \\
Total & 1298.233 & 102 & & & \\
\hline
\end{tabular}

a. Predictors: (Constant), X2_ACID, X1_Iptables

b. Dependent Variable: $Y \_$Keamanan Jaringan

Sumber: Pengolahan data

Berdasarkan pada hasil pengujian variabel secara simultan diketahui bahwa nilai $\mathrm{F}$ hitung sebesar 22,247 lebih besar dari nilai $\mathrm{F}$ tabel yaitu 3,93 dengan taraf signifikasinya adalah
0,000. Artinya, secara simultan (bersamasama) antara Iptables Firewall dan Analysis Console for Intrusion Database (ACID) secara bersamaan berpengaruh signifikan terhadap Keamanan Jaringan. 
Penelitian Bidang Komputer Sains dan Pendidikan Informatika V3.i2(157-164)

\section{SIMPULAN}

Dari hasil perhitungan dalam penelitian ini diketahui bahwa antara Iptables Firewall dan Analysis Console for Intrusion Database (ACID) secara bersamaan terdapat pengaruh secara signifikan terhadap Keamanan Jaringan pada Perusahaan di Kawasan Batamindo Industrial Park Batam sebesar 22,247\%.

\section{DAFTAR PUSTAKA}

Ariyus, Dony. (2005). Kamus Hacker. Edisi Pertama. C.V. Andi Offset. Yogyakarta.

Ariyus, Dony. (2008). Pengantar Ilmu Kriptografi Teori, Analisis, dan Implementasi. Edisi Pertama. C.V. Andi Offset. Yogyakarta.

Drive, 5 Maxwell. (2011). Penetration Testing Security Analysis. EC-Council Clifton Park.

Maslan, Andi dan Tonny Wangdra. (2012). Belajar Cepat teori, praktek dan simulasi jaringan komputer \& internet. Edisi Pertama. Baduose Media. Jakarta.

Na'am, Jufriadif, (2012). Teknik Keamanan Jaringan dan Data Dengan Linux Demilitarized Zone, Jurnal Ilmiah Processor STIKOM Dinamika Bangsa Jambi. 2 (7): 7 - 27.

Pangera, Abas Ali, Dony Ariyus. (2005). Sistem Operasi. Edisi Pertama. C.V. Andi Offset. Yogyakarta.

Rash, Michael. (2007). Linux Firewalls Attack Detection And Response With Iptables, Psad, And Fwsnort. No Starch Press, Inc. San Francisco.

Samuelle, T.J. (2009). Mike Meyer' Certification Passport Comptia Security+. Second Edition. McGraw-Hill Companies. United States of America.

Sofana, Iwan. (2008). Membangun Jaringan Komputer Mudah Membuat Jaringan Komputer (Wire \& Wireless) untuk Pengguna Windows dan Linux. Edisi Pertama. Informatika. Bandung.

Tittel, Ed. (2004). Schaum's Outlines Computer Networking (Jaringan Komputer). Erlangga. Jakarta.

Umar, Husein. (2011). Metode Penelitian untuk Skripsi dan Tesis Bisnis. Edisi Kedua. PT Rajagrafindo Persada. Jakarta.

Wibowo, Agung Edi. (2012). Aplikasi Praktis SPSS Dalam Penelitian. Edisi Pertama.
Gava Media. Yogyakarta.

Yani, Ahmad dan Fanny Hafiarny. (2005). Mudah dan Murah Membangun Jaringan Internet dengan Linux Router Project Leaf bearing. Edisi Pertama. PT Elex Media Komputindo. Jakarta. 